THE two laboratories in Great Britain which specialise in low temperature work, namely, the Clarendon Laboratory at Oxford, under Prof. F. A. Lindemann, and the Royal Society Mond Laboratory at Cambridge, under Prof. P. Kapitza, have offered the Museum their advice and assistance, and the Committee, under the chairmanship of $\mathbf{M r}$. H. T. Tizard, includes other well-known scientific workers and representatives of industrial organisations. The exhibition is primarily intended to show the properties of substances in the following low temperature regions :--solid carbon dioxide, liquid air, liquid hydrogen and liquid helium. As the use of these gases involves the liquefaction of gases obtained from the air, there will be exhibits to illustrate how the liquefaction and separation of these gases is performed in the laboratory and on an industrial scale, while the properties and uses of the gases and liquids will also come within the scope of the exhibition. The scheme is an ambitious one and there is no doubt that, with the support which the Science Museum has already received, it should result in an exhibition of great importance and interest. Col. Mackintosh desires that it should be comprehensive and he will welcome suggestions from anyone who has not so far been approached.

\section{The Radcliffe Observatory}

WHEN in the Court of Chancery on July $2 \mathrm{Mr}$. Justice Bennett approved in principle the application of the Radcliffe Trustees for permission to remove their observatory from Oxford to a site on the high veld near Pretoria, this project, which has been the subject of discussion for several years, reached a further and important stage in its development. Although the judge has reserved his final sanction of the scheme until he is satisfied as to certain details of law and finance, it is not anticipated that these will give rise to any serious difficulty. The Radcliffe Trustees have from the outset wished for some system of close co-operation between the observatory in South Africa and the University of Oxford, and it is intended that the scheme submitted to the judge for his final sanction shall set forth plans for such co-operation in a more concrete form than has hitherto been possible. The present buildings of the Radcliffe Observatory have to be vacated in the summer of next year, when they will be taken over by the Oxford Medical School, but several years must clearly elapse before the new observatory with its 72-inch telescope will be able to commence operations on the site on the hills outside Pretoria most generously presented by the municipality of that city. When it does, it will find waiting for it a vast field of nebulæ and faint stars yet unexplored with the spectroscope.

\section{Heavy Hydrogen}

THE intensive research on the new hydrogen isotope, 'heavy hydrogen', of mass 2 , and on its oxygen compound, 'heavy water', some aspects of which have been summarised in NATURE (132, 536, 1933 ; $133,197,881,1934)$, has given rise to an extensive literature. It was to be expected, therefore, that a monograph on the subject would be written, and two such have recently appeared. In that of Prof. E. Darmois ("Un Nouveau corps simple : le Deuterium ou Hydrogène Lourd", Actualités Scientifiques et Industrielles, No. 121. Paris, Hermann et Cie, 1934, pp. 24) - to consider them in alphabetical order of authors-a brief account of the course of discovery, the methods of separation, and the properties of heavy hydrogen and heavy water are reviewed, with useful numerical data. There is a short account of the utilisation of the deuterium (heavy hydrogen) nucleus in atomic disintegration, and of the compounds of deuterium apart from the oxide. The monograph of Prof. H. Mark ("Das Schwere Wasser". Leipzig and Vienna, F. Deuticke, 1934, pp. 32) covers much the same ground, but is rather fuller in some parts than that of Prof. Darmois, and the converse is also true, so that both monographs are necessary in obtaining information on the whole range of the subject up to the date when they were written. Readers of NATURE who desire information on the subject of heavy water will find these monographs very convenient and useful : it is noteworthy that many of the communications listed in the bibliographies have appeared in our columns.

\section{Chlorination of Water Supplies}

$\mathrm{AT}$ the recent annual meeting of the British Waterworks Association, Prof. P. S. Lelean dealt with the history and present state of the methods of chlorination of water supplies. The process was used in 1897 after an enteric outbreak at Maidstone, and its application on a large scale began in 1900 at Ostend; but the modern process, in which much smaller amounts of chlorine are used, was first put into operation in connexion with the London supplies on the initiative of the late $\mathrm{Sir}$ Alexander Houston. The method was extensively used during the War, when perfectly safe drinking water was procured in large amounts from canals and other sources of highly polluted water. In modern practice, bleaching powder has been replaced by chlorine from liquid chlorine. One part of chlorine in ten millions can. reduce Bacillus coli from 1,000 to 2 per c.c. in ten minutes. The chloramines formed by the action of chlorine on ammoniated water, however, are much more effective than chlorine alone. In the case of Thames water, an addition of 0.1 parts per million of ammonia, filtration, and addition of 0.25 parts per million of chlorine resulted in the absence of $B$. coli from 98 per cent of the samples of 100 c.c. Growth from spores is also considerably retarded. The process causes neither taste nor odour. Prof. Lelean dealt with many aspects of water chlorination in detail, and his lecture emphasised the very great service rendered to public health by the use of scientific methods by the authorities responsible for water supplies : in London, 280 million gallons per day are treated.

\section{Water Supplies in Rural Districts}

THE British Electrical Development Association, Inc., has recently issued a report on water supplies and sewage disposal in rural and small urban districts in Great Britain. The report is one which should be 
of use to many authorities who to-day are faced with the problem of improving water supplies. The extension of the electricity grid will naturally lead to the installation of electrical pumping plant in preference to steam and oil-driven plant on account of the possibility of automatic control. Many facts and figures as to cost and maintenance of plants and examples of installations are given, ranging from those suitable for a single house to those for large rural areas. In one district with a population of 17,000 spread over an area of 23,000 acres, a scheme was carried out for supplying $12 \frac{1}{2}$ gall. per head, the charge for which was approximately two shillings in the pound on the net annual value of the premises. The amount of water used will, of course, depend largely on the sewage system, but it is generally accepted that 25 gall. per head is a safe figure in planning a rural scheme.

\section{Guide Books and Museums}

Two guides to the palæontological collections of the British Museum (Natural History) have recently been issued. One of them, the "Guide to the Fossil Birds, Reptiles and Amphibians", claims to be "rather the first edition of a new Guide than a new edition of the old", while the other, the "Guide to the Fossil Mammals", is a reprint "altered and corrected where necessary" (London: British Museum (Natural History), 1s. each). Both guides call for criticism. In the first place it is a little difficult to know to what class of reader they are addressed. If for the serious student of palæontology, they are not sufficiently full and contain some rather serious errors, while to the visitor who only wishes to take an intelligent interest and have a little of the veil lifted, they are likely to be wellnigh unintelligible. This difficulty might perhaps be overcome by the use of material already to hand. In 1923 there was published a guide to the exhibition galleries of geology and palæontology, which, rewritten if necessary and with a few well-chosen illustrations, would serve the general public admirably and might be of use to the more elementary of the students. It may also be suggested that a series of separate guides, or guide leaflets, such as are to be found issued by the American Museum of Natural History, would serve a useful purpose. In fact, this plan is already partially in operation in the Natural History Museum. There is a "Guide to the Fossil Remains of Man", published in 1915 at a price of fourpence and a guide to the "Elephants (Recent and Fossil)" published as a second edition in 1922 for a shilling, both very satisfactory. Detailed criticism of the two guides under notice is out of place here, but it may be remarked that neither gives a clear idea of the evolution or classification of groups, while the purpose of some of the illustrations is obscure. It is to be hoped that the authorities will consider not a republication from time to time of matter which has served its purpose and has in course of time become obsolete, but an entire replanning and rewriting of guides to the national collections to meet the two distinct calls made on them, by the student and by the general public.

\section{Average Temperatures in the British Isles}

THE number of persons requiring information about the temperature normally experienced in different parts of the British Isles, for one purpose or another, has for many years been large enough to make it an important part of the work of the Meteorological Office to secure so far as possible that standard methods of obtaining air temperature shall be followed both at official and private meteorological stations, and that summaries of these records in comparable form shall be available for inquirers. In a recent handbook ("Averages of Temperatures for the British Isles." H.M. Stationery Office. 9d., postage extra) monthly and annual averages of the daily maximum and minimum temperature are given, so far as possible, for the years 1901-1930. As there are, however, many stations for which the averages can refer to only a portion of that period, the inquirer has to be warned against indiscriminate comparisons; for example, differences between a pair of stations for which the period of years referred to is not the same may be due more to peculiarities of the two periods than to real climatic differences ; there is the further pitfall of possible differences in times of setting of the maximum and minimum thermometers at the two places. These matters are dealt with in the introduction and the necessary information is shown against each set of figures. It may be observed that the precise meaning of the 'normal' or 'average' maximum or minimum temperature for a given season and a given place is not easily defined. In Table I of the "Book of Normals", which the tables under review supersede, the mean temperature at Kew in January (or rather the mid-point between the mean daily maximum and mean daily minimum) is given as $38.9^{\circ} \mathrm{F}$., whereas in the new tables it appears as $40 \cdot 4^{\circ} \mathrm{F}$. The relatively low figure in the "Book of Normals" is due partly to the fact that in the period covered therein (1881-1915) there was a notable run of cold winters, those of the early 'nineties, while the winters of 1901-30 have mostly been mild; there is no means of knowing whether the next 30 years will give an average or 'normal' near to $38 \cdot 9^{\circ} \mathrm{F}$. or one nearer to $40 \cdot 4^{\circ}$.

\section{British Empire Broadcasting}

Some of the difficulties overcome by the British Broadcasting Corporation in establishing a broadcast service between Great Britain and distant regions of the Empire are well described in a paper in Electrical Communication of April by C. M. Benham and P. H. Spagnoletti. Except in special cases, long distance radio communication is practical only when short wave-lengths are used. It was necessary therefore to use radio equipment of the short wave type. Fortunately, the colonies and dominions are so distributed longitudinally that they can be conveniently divided into time zones, that is, areas which have approximately the same local time. There are four main zones: Australia, which has a time displacement relative to London of 'eight hours early'; India, 'four hours early'; Africa, the same time; and Canada, 'six hours late'. In the case 